\title{
Mosquitoes infected with dengue viruses in Brazil
}

\author{
Mario LG de Figueiredo', Almério de C Gomes², Alberto A Amarilla 3 , André de S Leandro4, Agnaldo de S Orrico5, \\ Renato F de Araujo5, Jesuína do SM Castro5, Edison L Durigon'1, Victor H Aquino ${ }^{6}$ and Luiz TM Figueiredo*3
}

\begin{abstract}
Dengue epidemics have been reported in Brazil since 1985. The scenery has worsened in the last decade because several serotypes are circulating and producing a hyper-endemic situation, with an increase of DHF/DSS cases as well as the number of fatalities. Herein, we report dengue virus surveillance in mosquitoes using a Flavivirus genus-specific RT-Hemi-Nested-PCR assay. The mosquitoes (Culicidae, $n=1700$ ) collected in the Northeast, Southeast and South of Brazil, between 1999 and 2005, were grouped into 154 pools. Putative genomes of DENV-1, -2 and -3 were detected in 6 mosquito pools (3.8\%). One amplicon of putative DENV-1 was detected in a pool of Haemagogus leucocelaenus suggesting that this virus could be involved in a sylvatic cycle. DENV-3 was found infecting 3 pools of larvae of Aedes albopictus and the nucleotide sequence of one of these viruses was identified as DENV-3 of genotype III, phylogenetically related to other DENV-3 isolated in Brazil. This is the first report of a nucleotide sequence of DENV-3 from larvae of Aedes albopictus.
\end{abstract}

\section{Findings}

Dengue viruses (family Flaviviridae, genus Flavivirus), serotypes 1 to 4 (DENV-1, -2, -3 and -4), are responsible for large urban outbreaks. Infection with any of the four dengue virus serotypes can lead to acute febrile illness and to the severe, sometimes fatal, dengue hemorrhagic fever/dengue shock syndrome (DHF/DSS) [1].

DENV are transmitted to humans mainly by Aedes aegypti mosquitoes, which acquired the infection through blood-feeding on infected individuals or by transovarial transmission [2]. Besides, in Africa and Asia, DENV have been reported in sylvatic (enzootic) cycle involving non-human primates and various species of Aedes mosquito (such as Ae. furcifer, Ae. luteocephalus and Ae. taylori) [3].

The first viral isolation in Brazil was reported in 1981 in Roraima Sate, Northern Brazil, where DENV-1 and DENV-4 were isolated and associated with dengue cases. DENV-1 and DENV-2 were introduced in Rio de Janeiro, in 1985 and 1990, respectively; then, both viruses co-circulate for 10 years causing several outbreaks in the country, including many cases of dengue hemorrhagic fever. In 2000, DENV-3 was introduced in Rio de Janeiro State and then spread to all the country, co-circulating with DENV-

\footnotetext{
* Correspondence: Itmfigue@fmrp.usp.br

3 Virology Research Center, School of Medicine of Ribeirao Preto, University of Sao Paulo, Ribeirao Preto, Brazil

Full list of author information is available at the end of the article
}

1 and DENV-2. Finally, DENV-4 was isolated from dengue fever cases in Manaus at Amazon State, in 2005, suggesting its circulation in that City $[4,5]$. Actually, Brazil is facing a hyper-endemic situation with increase number of DHF/DSS in children and fatal cases [6,7].

Herein, we report results of dengue virus surveillance in mosquitoes using a RT-Hemi-Nested-PCR assay.

Using light traps in the soil and the top of the trees, 1700 mosquitoes (Culicidae, Diptera) were captured in three different places of Brazil (Table 1), where dengue outbreaks have been reported [8]. Thus, in Coribe

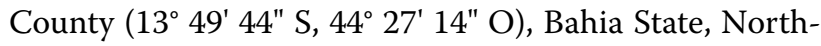
east region, 644 mosquitoes were collected in the rain forest, in 2002. In the City of Foz do Iguaçu ( $25^{\circ} 32^{\prime} 52^{\prime \prime} \mathrm{S}$, $\left.54^{\circ} 25^{\prime} 16^{\prime \prime} \mathrm{O}\right)$, Parana State, South region, 370 mosquitoes were collected at urban area, in 2005. In the City of

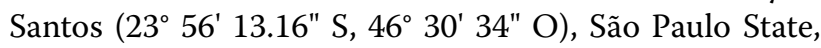
Southeast region, 686 mosquitoes were collected in the urban area, in 1999. In addition, larvae were collected from domestic and peridomestic containers.

Mosquitoes and larvae were identified in $\mathrm{CO}_{2}$ atmosphere, based on morphologic characteristics [9] and those from the same specie or genus, captured in the same place, were pooled ( 10 adult or larvae mosquitoes/ pool) based on day of collection and stored at $-70^{\circ} \mathrm{C}$ (Table 1). To each mosquito pool, $1.5 \mathrm{ml}$ of $4 \%$ bovine albumin in PBS ( $\mathrm{pH} 7.8$ ) were added. The specimens were 
Table 1: Origin and number of Culicidae (Diptera) collected for the study.

\begin{tabular}{|c|c|c|c|c|c|c|}
\hline Collection places & Species & Adults & Larvae & Males & Females & Number of pools \\
\hline Coribe County & Psorophora albipes & 50 & - & - & 50 & 5 \\
\hline Coribe County & Psorophora albigenus & 50 & - & - & 50 & 5 \\
\hline Coribe County & Psorophora ferox & 60 & - & - & 60 & 6 \\
\hline Coribe County & Haemagogus jantinomys & 64 & - & 10 & 54 & 9 \\
\hline Coribe County & Haemagogus leucocelaenus & 171 & - & 1 & 170 & 21 \\
\hline Coribe County & Haemagogus spegazzinii & 249 & - & 241 & 8 & 21 \\
\hline $\begin{array}{l}\text { City of Foz do } \\
\text { Iguacu }\end{array}$ & Aedes Aegypti & 370 & - & 19 & 403 & 51 \\
\hline City of Santos & Aedes aegypti & 56 & - & 13 & 43 & 4 \\
\hline City of Santos & Aedes albopictus & 88 & 542 & 39 & 49 & 32 ( 6 of adults and 26 of larvae) \\
\hline Total & & 1158 & 542 & 323 & 887 & 154 \\
\hline
\end{tabular}

crushed using grind and mortar, and centrifuged at 2500 $\times \mathrm{g}$, for 30 minutes, at $4^{\circ} \mathrm{C}$. The supernatants were split in two aliquots and stored at $-80^{\circ} \mathrm{C}$ until use [10].

RNA from the supernatant of macerated mosquito samples was extracted using the Qiamp Viral RNA Kit (QIAGEN, USA). RNA extracts were subjected to a Flavivirus genus-specific RT-Hemi-Nested-PCR that allows the identification of DENV-1 to 4, YFV, ILH, SLEV, BSQV and ROCV [11]. The size of the amplification products suggests the presence of DENV genomes in $6(3.8 \%)$ pools (Figure 1), and the information on theses mosquitoes is summarized in Table 2. Amplicons having DENV1 compatible size were obtained from a pool of Haemagogus leucocelaenus captured in Coribe County and from adult females of Aedes aegypti capture in Santos City [11]. One amplicon with DENV-2 compatible size was amplified from a pool of Aedes aegypti captured in Foz do Iguaçu City [11]. Finally, DENV-3 compatible amplicon was obtained from 3 pools of larvae of Aedes aegypti collected in Santos [11].

The amplicon of DENV-3 obtained from the pool of larvae of Aedes albopictus was directly sequenced after purification from the agarose gel with the QUIAquick gel extraction (Qiagen, USA). The purified product was sequenced in an ABI PRISM ${ }^{\circ} 3100$ Genetic Analyzer (Applied Biosystems, Foster City, CA-USA). The obtained 568 base pair sequence, named D3/BR/Santos/ A. albopictus 13/1999, was registered in the GenBank with the accession number HM053487. This sequence was aligned with 569 worldwide DENV-3 retrieved from GenBank using the program CLUSTAL W software [12]. The alignment was edited with the software MEGA 4.0 [13]. The phylogenetic relationship among strains was reconstructed by the neighbor-joining (NJ) using MEGA 4.0. The analyses were supported by bootstrap using 1000 replicates. Figure 2 shows the phylogenetic tree with the characteristic distribution of DENV-3 in four genotypes, as previously reported $[14,15]$. The sequence obtained in this study grouped in the genotype III together with Brazilian strains. The other amplicons could no be sequenced because of the small quantity of the products.

All procedures were performed in order to avoid any type of contamination; different rooms were used for

Table 2: Information on 6 mosquito pools having flavivirus genome amplified by RT-nested-PCR .

\begin{tabular}{|c|c|c|c|c|c|}
\hline Collection places & Date of Collection & Genera & Specie & Amplicon size & Virus \\
\hline Coribe County & 2002 & Female & H. leucocelaenus & $\sim 472 \mathrm{pb}$ & DENV-1 \\
\hline City of Foz do Iguacu & 2005 & Female & Ae. Aegypti & $\sim 316 \mathrm{pb}$ & DENV-2 \\
\hline City of Santos & 1999 & Larvae & Ae. albopictus & $\sim 628 \mathrm{pb}$ & DENV-3 \\
\hline City of Santos & 1999 & Larvae & Ae. albopictus & $\sim 628 \mathrm{pb}$ & DENV-3 \\
\hline City of Santos & 1999 & Larvae & Ae. albopictus & $\sim 628 \mathrm{pb}$ & DENV-3 \\
\hline City of Santos & 1999 & Female & Ae. Aegypti & $\sim 472 \mathrm{pb}$ & DENV-1 \\
\hline
\end{tabular}

The sequenced amplicon is shown in bold. 


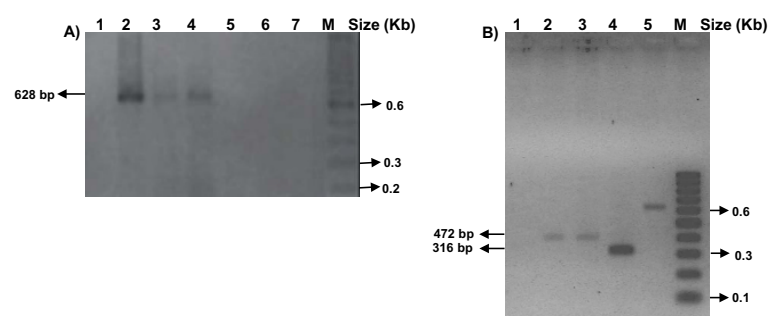

Figure 1 Agarose gel electrophoresis showing amplicons obtained by the RT-Hemi-Nested-PCR for flavivirus from mosquitoes and larvae. $\boldsymbol{A}$ ) Lanes 1 to 7 include amplification reaction products from larvae of Aedes albopictus from the City of Santos. Amplicon of $\sim 628$ bp compatible with DENV-3 in lanes 2, 3 and 4. B) Amplicon of $\sim 472 \mathrm{bp}$, compatible with DENV-1, are shown in lanes 2 (Aedes aegypti of the City of Santos) and 3 (Haemagogus leucocelaenus from the County of Coribe). Line 4 shows an amplicon band of $\sim 316$ bp, compatible with DENV-2, obtained from Aedes aegypti captured in Foz do Iguaçu City. Lane 1 is a negative control and lane 5 is a positive control (DENV-3) of the RT-Hemi-Nested-PCR reaction.

RNA purification, NS5 protein gene amplification and PCR products analysis.

The RT-Hemi-Nested-PCR method used in this study has been shown previously to be a reliable diagnostic tool to detect flavivirus infection in humans [16]. We were able to obtain amplicons of putative DENV-1, DENV-2 and DENV-3, and one of the amplicons was confirmed to be DENV-3 by nucleotide sequencing.

A putative DENV-1 was detected infecting females of Aedes aegypti captured in Santos in 1999, at the same time of an outbreak with 4685 reported cases [17].

In addition, a putative DENV-2 was also found infecting the same specie of mosquito captured in Foz do Iguaçu and a putative DENV-1 was detected infecting the same mosquito species from Santos. Aedes aegypti, an anthropofilic and urban mosquito, is the most important dengue vector in the Americas and is present in practically all Brazilian cities [18].

Interestedly, we have found putative DENV-1 infecting females of Haemagogus leucocelaenus collected in a rain forest of the Northeast of Brazil. This finding might suggest a sylvatic cycle of the virus as previously reported in Africa with DENV-2 and in Asia with DENV-1, -2 and -4, involving non-human primates $[3,19]$. This may also represent the beginning of sylvatic adaptation of a virus circulating in the urban area. A similar phenomenon has previously occurred with the African YFV, which lead to urban epidemics after its introduction in the Americas, but then, suffered a processes of adaptation to a sylvatic cycle in Haemagogus janthynomis, leucocelaenus and Sabethes spp., and non-human primates [20]. Equally, the sylvatic DENV in Asia is maintained in an enzootic cycle, mainly circulating in canopy-dwelling monkeys, with infrequent spillover to human populations via Aedes spp. that feed on both upper and lower canopy primates [21]. Besides, the four serotypes of DENV have been recently reported in French Guyana infecting rodents, marsupials, chiroptera, and showing that sylvatic cycles are occurring in South America [22]. It is known that sylvatic strains of DENV are genetically distinct of the endemic viruses [21]. However, it was not possible to obtain the nucleotide sequence of the amplicon of the putative DENV-1 infecting Haemagogus leucocelaenus. Further studies are necessary in order to confirm that DENV-1 is infecting Haemagogus in Brasil.

Putative DENV-3 was found infecting 3 pools of Aedes albopictus larvae collected in 1999, in Santos City, at the coast of São Paulo, the most populated state of Brazil. The sequence of one of these viruses was identified as DENV-3 of genotype III, phylogenetically related to Brazilian isolates. As far as we know, this is the first nucleotide sequence of DENV-3 ever reported from larvae of Aedes albopictus. DENV-3 of genotype III was firstly reported in Brazil in 2000 in Rio de Janeiro [23]. However, based on our data, we can suppose that DENV-3 genotype III was introduced in the Brazilian Southeast coast before 2000. It was also recognized another introduction of DENV-3 genotype III at the North of the country [8]. This finding also suggests that Aedes albopictus could have participated as vector in the huge dengue outbreaks occurred in the Brazilian coast. Furthermore, the infection of larvae of Aedes albopictus is an evidence of transovarial transmission of DENV-3, as previously reported with DENV-1 [24]. Aedes albopictus is a mosquito from Asia that was introduced in Brazil by merchant ships. This mosquito is not as antropophilic as Aedes aegypti and can be found in both urban and rural areas [25]. The vertical transmission of DENV ensures presence of the pathogen in mosquitoes independent of their feeding upon an infective human blood carrying DENV. This virus retention across mosquito generations may serve to keep DENV in nature during inter-epidemic periods of the disease being a possible cause of reemergence of dengue in areas previously exposed to the virus. It also may have importance for amplifying an ongoing disease outbreak $[26,27]$.

Laboratory-based mosquito surveillance is important to provide an early warning of dengue fever epidemics, to furnish information on who are the vectors carrying DENV in nature and what is happening in terms of virus transmission during these outbreaks. This knowledge is crucial for vector control measures since we still do not have a dengue vaccine. The RT-nested-PCR used in the present study allowed a fast detection and typing of DENV and other flavivirus in the mosquitoes. 


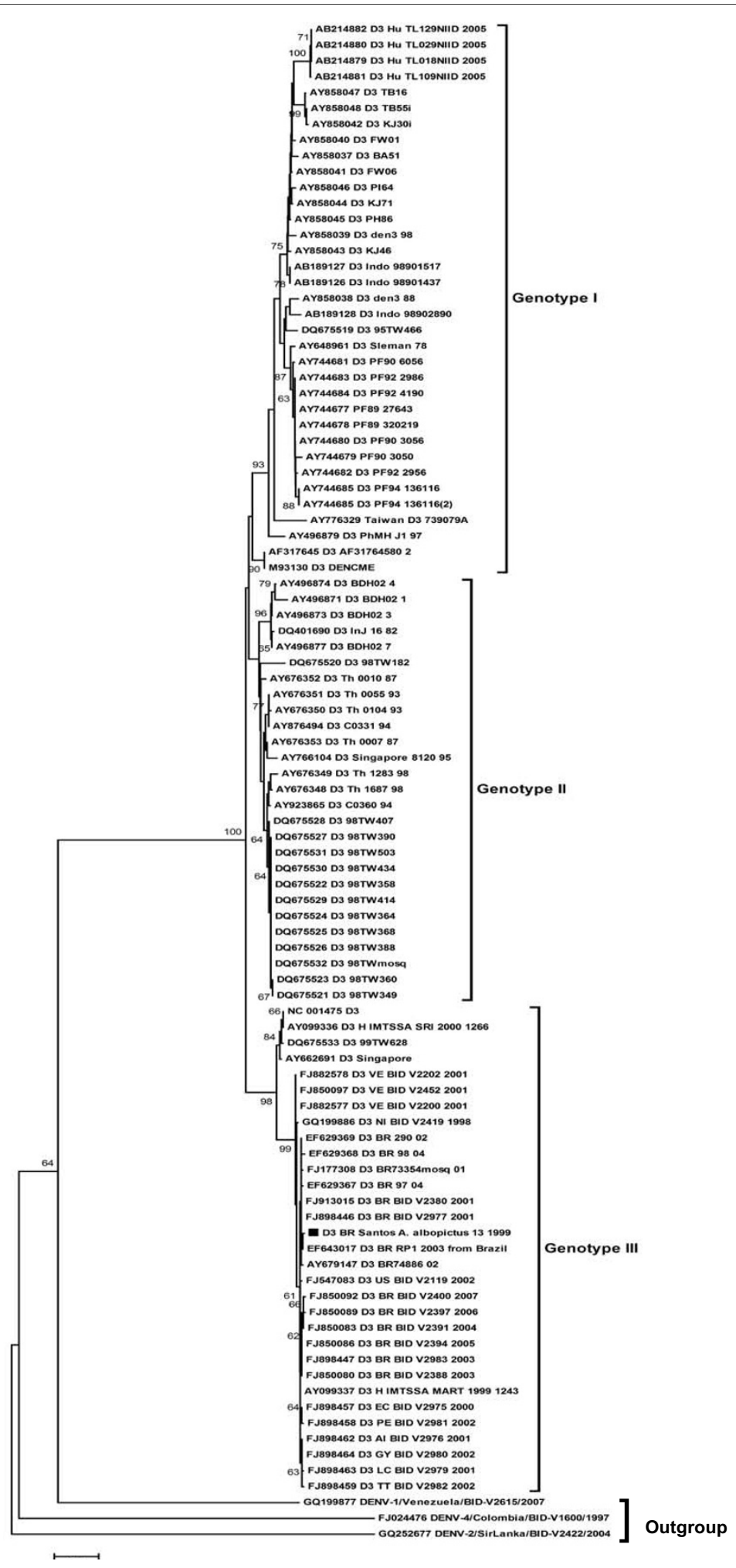

Figure 2 DENV-3 phylogenetic tree based on the NS5 partial gene sequences. The three was constructed using the method of Neighbor-joining with 1000 bootstrap replications. The genotypes are labeled according to the scheme of Lanciotti in 1994 [14] and Amarilla in 2009 [15]. DENV-1, DENV-2 and DENV-4 were used as outgroup. Branch lengths are proportional to percentage of divergence. Tamura Nei (TrN+G) nucleotide substitution model was used with a gamma distribution (G) of 0.5121 . Bootstrap support values are shown for key nodes only (values $<70 \%$ not shown). The strains isolated D3/BR/Santos/A. albopictus 13/1999 is marked with a filled square. The GenBank accession numbers, species, the country of origin, and year of isolation are shown. 


\section{Competing interests}

The authors declare that they have no competing interests.

\section{Authors' contributions}

MLGF, ACG, AAA, VHA and LTMF conceived of the study, and participated in its design and coordination. All authors read and approved the final manuscript.

\section{Acknowledgements}

We acknowledge the Research Council of the State of São Paulo (FAPESP) and the Research Council of the Brazilian Federal Government (CNPq) for supporting this research.

\section{Author Details}

'Institute of Biomedical Sciences of the University of Sao Paulo, Sao Paulo, Brazil, ${ }^{2} S$ chool of Public Health of the University of Sao Paulo, Sao Paulo, Brazil, ${ }^{3}$ Virology Research Center, School of Medicine of Ribeirao Preto, University of Sao Paulo Ribeirao Preto, Brazil, ${ }^{2}$ Zoonosis Center of the City of Foz do Iguaçu, PR, Brazil, ${ }^{5}$ Ministry of Health of the State of Bahia, Salvador, BH, Brazil and ${ }^{6}$ Department of Clinical, Toxicological and Bromatological Analysis, School of Pharmaceutical Sciences of Ribeirao Preto, University of Sao Paulo, Ribeirao Preto, Brazil

Received: 6 April 2010 Accepted: 12 July 2010

Published: 12 July 2010

\section{References}

1. WHO: World Health Organization. Dengue and Dengue Haemorrhagic Fever. Fact Sheet No. 117. Geneva 2009.

2. Joshi V, Mourya D, Sharma R: Persistence of dengue-3 virus through transovarial transmission passage in successive generations of Aedes aegypti mosquitoes. Am J Trop Med Hyg 2002, 67:158-161.

3. Cardosa J, Ooi M, Tio P, Perera D, Holmes E, Bibi K, Abdul Manap Z: Dengue virus serotype 2 from a sylvatic lineage isolated from a patient with dengue hemorrhagic fever. PLoS Negl Trop Dis 2009, 3:e423.

4. Fonseca B, Figueiredo L: Dengue. In Tratado de Infectologia 4th edition. Edited by: Focaccia R. São Paulo: Atheneu; 2010:397-410.

5. Figueiredo R, Naveca F, Bastos M, Melo M, Viana S, Mourão M, Costa C, Farias I: Dengue virus type 4, Manaus, Brazil. Emerg Infect Dis 2008, 14:667-669.

6. San Martín J, Brathwaite O, Zambrano B, Solórzano J, Bouckenooghe A, Dayan G, Guzmán M: The epidemiology of dengue in the americas over the last three decades: a worrisome reality. Am J Trop Med Hyg 2010, 82:128-135

7. Da Rocha L, Tauil P: Dengue em criança: aspectos clínicos e epidemiológicos, Manaus, Estado do Amazonas, no período de 2006 e 2007. Revista da Sociedade Brasileira de Medicina Tropical 2009, 42:18-22.

8. Aquino VH, Anatriello E, Goncalves PF, da Silva EV, Vasconcelos PFC, Vieira DS, Batista WC, Bobadilla ML, Vazquez C, Moran M, Figueiredo LTM: Molecular epidemiology of dengue type 3 virus in Brazil and Paraguay, 2002-2004. American Journal of Tropical Medicine and Hygiene 2006, 75:710-715

9. Forattini O: Culicidologia Médica: Identificação, Biologia, Epidemiologia, São Paulo 2002.

10. Huang C, Slater B, Campbell W, Howard J, White D: Detection of arboviral RNA directly from mosquito homogenates by reverse-transcriptionpolymerase chain reaction. J Virol Methods 2001, 94:121-128.

11. de Morais Bronzoni R, Baleotti F, Ribeiro Nogueira R, Nunes M, Moraes Figueiredo L: Duplex reverse transcription-PCR followed by nested PCR assays for detection and identification of Brazilian alphaviruses and flaviviruses. J Clin Microbiol 2005, 43:696-702.

12. Thompson J, Gibson T, Plewniak F, Jeanmougin F, Higgins D: The CLUSTAL_X windows interface: flexible strategies for multiple sequence alignment aided by quality analysis tools. Nucleic Acids Res 1997, 25:4876-4882

13. Tamura K, Dudley J, Nei M, Kumar S: MEGA4: Molecular Evolutionary Genetics Analysis (MEGA) software version 4.0. Mol Biol Evol 2007, 24:1596-1599.

14. Lanciotti R, Lewis J, Gubler D, Trent D: Molecular evolution and epidemiology of dengue-3 viruses. J Gen Virol 1994, 75(Pt 1):65-75.

15. Amarilla A, de Almeida F, Jorge D, Alfonso H, de Castro-Jorge L, Nogueira $\mathrm{N}$, Figueiredo L, Aquino V: Genetic diversity of the E protein of dengue type 3 virus. Virol J 2009, 6:113.
16. Mondini A, Cardeal I, Lázaro E, Nunes S, Moreira C, Rahal P, Maia I, Franco C, Góngora D, Góngora-Rubio F, et al.: Saint Louis encephalitis virus, Brazil. Emerg Infect Dis 2007, 13:176-178.

17. SUCEN: DIRXIX, Santos, Ministry of Health of the State of São Paulo. 2000.

18. Gubler D: Resurgent vector-borne diseases as a global health problem. Emerg Infect Dis 1998, 4:442-450.

19. Wang E, Ni H, Xu R, Barrett A, Watowich S, Gubler D, Weaver S: Evolutionary relationships of endemic/epidemic and sylvatic dengue viruses. J Virol 2000, 74:3227-3234.

20. Vasconcelos P, Bryant J, da Rosa T, Tesh R, Rodrigues S, Barrett A: Genetic divergence and dispersal of yellow fever virus, Brazil. Emerg Infect Dis 2004, 10:1578-1584.

21. Pepin K, Hanley K: Density-dependent competitive suppression of sylvatic dengue virus by endemic dengue virus in cultured mosquito cells. Vector Borne Zoonotic Dis 2008, 8:821-828.

22. de Thoisy B, Lacoste V, Germain A, Muñoz-Jordán J, Colón C, Mauffrey J, Delaval M, Catzeflis F, Kazanji M, Matheus S, et al:: Dengue infection in neotropical forest mammals. Vector Borne Zoonotic Dis 2009, 9:157-170.

23. Nogueira R, Miagostovich M, de Filippis A, Pereira M, Schatzmayr H: Dengue virus type 3 in Rio de Janeiro, Brazil. Mem Inst Oswaldo Cruz 2001, 96:925-926.

24. Serufo J, de Oca H, Tavares V, Souza A, Rosa R, Jamal M, Lemos J, Oliveira $M$, Nogueira R, Schatzmayr H: Isolation of dengue virus type 1 from larvae of Aedes albopictus in Campos Altos city, State of Minas Gerais, Brazil. Mem Inst Oswaldo Cruz 1993, 88:503-504.

25. Consoli R, Oliveira R: Principais mosquitos de importância sanitária no Brasil Rio de Janeiro: Fundação Oswaldo Cruz; 1994.

26. Angel B, Sharma K, Joshi V: Association of ovarian proteins with transovarial transmission of dengue viruses by Aedes mosquitoes in Rajasthan, India. Indian J Med Res 2008, 128:320-323.

27. Angel $B$, Joshi V: Distribution and seasonality of vertically transmitted dengue viruses in Aedes mosquitoes in arid and semi-arid areas of Rajasthan, India. J Vector Borne Dis 2008, 45:56-59.

doi: $10.1186 / 1743-422 X-7-152$

Cite this article as: de Figueiredo et al,, Mosquitoes infected with dengue viruses in Brazil Virology Journal 2010, 7:152

\section{Submit your next manuscript to BioMed Central and take full advantage of:}

- Convenient online submission

- Thorough peer review

- No space constraints or color figure charges

- Immediate publication on acceptance

- Inclusion in PubMed, CAS, Scopus and Google Scholar

- Research which is freely available for redistribution
C Biomed Central 